\title{
THROMBOCYTOPENIA AMONG TRAUMA PATIENTS ADMITTED IN ICU: FREQUENCY AND RELATIONSHIP WITH OUTCOME
}

\author{
Aamir Farukh, Ejaz Ahmad, Zahid Farooq Baig, Umair Ahmad Siddique, Tariq Bashir Tareen, Aslam Khan \\ Combined Military Hospital Peshawar/National University of Medical Sciences (NUMS) Pakistan
}

\begin{abstract}
Objective: To assess the frequency of thrombocytopenia among the patients of trauma at an intensive care unit and to look for its relationship and other socio-demographic factors with the outcome.

Study Design: Cross-sectional study.

Place and Duration of Study: Intensive Care Unit, Combined Military Hospital Peshawar, from Mar to Aug 2017.

Methodology: Thrombocytopenia was defined as platelet count of $<150,000 / \mu l$ and was performed on the fifth day of admission in the Intensive Care Unit. Age, gender, presence of thrombocytopenia, history of platelet transfusion, and length of stay in the Intensive Care Unit were correlated with the outcome in our study population.

Results: A total of 107 patients admitted to intensive care unit with traumatic injuries during the study period were included in analysis. Mean age of the patients was $37.93 \pm 6.697$ years. Thrombocytopenia developed in $35(32.7 \%)$ of the patients while $72(67.3 \%)$ had normal platelet count. Less than $18 \%$ patients died in the intensive care unit. Long duration of Intensive Care Unit stay and presence of thrombocytopenia were statistically significantly associated $(p<0.05)$ with the presence of poor outcome in our sample population.

Conclusion: Frequency of thrombocytopenia was high among patients admitted with trauma in intensive care unit and was also related to poor outcome in these patients.
\end{abstract}

Keywords: Intensive care unit, Outcome, Thrombocytopenia.

How to Cite This Article: Farukh A, Ahmad E, Baig ZF, Siddique UA, Tareen TB, Khan A. Thrombocytopenia Among Trauma Patients Admitted in ICU: Frequency and Relationship with Outcome. Pak Armed Forces Med J 2021; 71(5): 1630-1632. doi: https://doi.org/10.51253/pafmj.v71i5.2369

This is an Open Access article distributed under the terms of the Creative Commons Attribution License (https://creativecommons.org/licenses/by-nc/4.0/), which permits unrestricted use, distribution, and reproduction in any medium, provided the original work is properly cited.

\section{INTRODUCTION}

Trauma is one of the leading cause of death among all the age groups specially the young. ${ }^{1}$ Our country is facing a similar challenge and traumatic injuries are on a rise posing a great burden on overall health care budget. ${ }^{2}$ Critical care medicine specialized for trauma patients is an emerging specialty with very limited scope in the low and middle income countries countries. $^{3}$

Normal hematological parameters are necessary for the overall homeostasis of the human body. Platelets are one of the most important components of human blood and play the main role in hemostasis on exposure to trauma and other conditions of injury to the body. ${ }^{4}$ Thrombocytopenia has been studied with various non-hematological conditions including medical and surgical conditions. Some of them are pregnancy, sepsis, malaria, typhoid and cholecystitis. ${ }^{5-8}$ Various factors have been correlated with the development of thrombocytopenia in the intensive care settings. Some of them include age, severity of underlying illness, co-

Correspondence: Dr Aamir Farukh, Intensive Care Unit, Combined Military Hospital Peshawar Pakistan

Received: 27 Jan 2019; revision received: 06 Oct 2020; accepted: 09 Oct 2020 morbid illnesses, duration of ICU stay, presence of associated renal injury and APACHE III score at time of presentation. ${ }^{9,10}$ These factors may cause thrombocytopenia by physical, physiological or immunological mechanisms among the patients admitted and treated vigorously in the critical care setting.

Limited local data was available on thrombocytopenia in ICU patients in our part of the world. This study was planned with the objective to look for the frequency of thrombocytopenia among the patients of trauma at an ICU and look for its relationship and other socio-demographic factors with the outcome.

\section{METHODOLOGY}

This cross-sectional study was conducted at the Intensive Care Unit of Combined Military Hospital Peshawar from March to August 2018. All patients of trauma admitted to ICU during this period were included in this study using non probability consecutive sampling technique. Sample size was calculated by using the population prevalence proportion of thrombocytopenia in critically ill as $9 \% .{ }^{11}$

Inclusion Criteria: Patients between the age of 18 and 60 years admitted in intensive care unit for at least five days after any traumatic injury. This included patients 
who were referred from other military, public sector and private hospitals who required the admission in critical care unit and also patients shifted from other wards of the hospital were also included.

Exclusion Criteria: The patients shifted before five days from ICU were excluded from the study. In addition, patients with malignancies, autoimmune disorders, chronic liver disease and pregnant women were also excluded from the study.

After ethical approval from the ethical review board committee and written informed consent from the patient or their care-givers, patients who were admitted after traumatic injuries in the intensive care unit of $\mathrm{CMH}$ Peshawar fulfilling the above mentioned inclusion and exclusion criteria were included in the study. Intensive care unit is a twelve bedded facility with around 450 admissions per year for various ailments requiring the organ support. The diagnosis of thrombocytopenia was made with platelet count of $<150,000 / \mu 1$ which was performed on the fifth day of admission in the ICU.12-14 Age, gender, presence of thrombocytopenia, history of platelet transfusion, and length of stay in the ICU were correlated with the outcome in our study population. Good outcome included shift of the patient to the ward or step down unit and poor outcome was death of the patient.

Characteristics of patients and the distribution of the outcome were described by using the descriptive statistics. Chi-square was used to determine betweengroup variances in categorical variables. Differences between groups were considered significant if $p$-values were $\leq 0.05$.

\section{RESULTS}

A total of 119 patients were initially approached to get them included in the analysis, out of which twelve patients were excluded due to different reasons, seven patients were out of the age bracket of inclusion criteria, one had leukemia prior to admission in ICU and two patients were pregnant. Care-givers of two patients did not give consent to include them in the study. Out of 107 patients included in the final analysis $92(85.9 \%)$ were male and $15(14.1 \%)$ were female. Mean age of patients admitted with trauma in ICU was $37.93 \pm 6.697$ years. Table shows that out of 107 patients, $35(32.7 \%)$ developed thrombocytopenia while $72(67.3 \%)$ had normal platelet count, $19(17.8 \%)$ of the patients had a poor outcome, presence of thrombocytopenia $(p=0.002)$ and long duration of ICU stay $(p=$ 0.001) had significant association.
Table-I: Characteristics of the study group and outcome in the patients of trauma admitted in ICU.

\begin{tabular}{|c|c|c|c|}
\hline Parameters & $\begin{array}{c}\text { Good Outcome } \\
\text { n (\%) } 88(82.2)\end{array}$ & $\begin{array}{l}\text { Poor Outcome } \\
\text { n (\%) } 19(17.8)\end{array}$ & $p$-value \\
\hline \multicolumn{4}{|l|}{ Age } \\
\hline $\begin{array}{l}\leq 35 \text { years } \\
35-60 \text { years }\end{array}$ & $\begin{array}{l}38(43.2 \%) \\
50(56.8 \%)\end{array}$ & $\begin{array}{l}06(31.6 \%) \\
13(68.4 \%)\end{array}$ & 0.345 \\
\hline \multicolumn{4}{|l|}{ Gender } \\
\hline $\begin{array}{l}\text { Male } \\
\text { Female }\end{array}$ & $\begin{array}{l}75(85.2 \%) \\
13(14.8 \%)\end{array}$ & $\begin{array}{l}17(89.4 \%) \\
02(10.6 \%)\end{array}$ & 0.618 \\
\hline \multicolumn{4}{|c|}{ Duration of ICU Stay } \\
\hline $\begin{array}{l}<1 \text { week } \\
\geq 1 \text { week }\end{array}$ & $\begin{array}{l}76(86.3 \%) \\
12(13.7 \%) \\
\end{array}$ & $\begin{array}{l}10(52.6 \%) \\
09(47.4 \%)\end{array}$ & 0.001 \\
\hline \multicolumn{4}{|c|}{ History of Platelet Ransfusion } \\
\hline $\begin{array}{l}\text { No } \\
\text { Yes }\end{array}$ & $\begin{array}{l}64(72.7 \%) \\
24(27.3 \%)\end{array}$ & $\begin{array}{l}16(84.2 \%) \\
03(15.8 \%)\end{array}$ & 0.277 \\
\hline \multicolumn{4}{|c|}{ Thrombocytopenia } \\
\hline $\begin{array}{l}\text { No } \\
\text { Yes }\end{array}$ & $\begin{array}{l}65(73.9 \%) \\
23(26.1 \%)\end{array}$ & $\begin{array}{l}07(36.8 \%) \\
12(63.2 \%)\end{array}$ & 0.002 \\
\hline
\end{tabular}

\section{DISCUSSION}

Trauma is a major problem worldwide. Apart from morbidity and mortality, it puts a lot of economic burden on individuals and countries. ${ }^{15-18}$ There is a global trend of male predominance in trauma patients as pointed out by Agarwal et al, Stephan et al, and Koyamak et al,10,20,21 but is specifically high in our study. The likely reason is that the law enforcing agencies mostly consist of male gender in Pakistan and $\mathrm{CMH}$ Peshawar receives the main bulk of casualties from operational areas and females in our set up have lesser chance of receiving critical traumatic injuries.

Outcome in our patients was very promising i.e. most of our patients had a good outcome and they were stepped down either to HDU or surgical ward. Less than 20 percent of them died during the ICU stay. This outcome was better than the outcome seen in past studies done on similar patients especially study conducted by martini et al,22 Reason might be age of our patients as most of our patients were young or it might be the flaw of study design as long term follow up was not scope of our study.

Presence of thrombocytopenia has been associated with the presence of poor outcome after the trauma in a critical care setting. Studies of Goliriz et al, and Stephan et al, have been important in this regard.8,11 Results in our study were similar and thrombocytopenia emerged as independent risk factor relate to the poor outcome in ICU patients of our population. Decrease in the platelet count effect their functionality as well. There might be a bi-directional link between thrombocytopenia and underlying illness which worsen the prognosis among these patients. 
High mortality rate has been a problem in intensive care units all over the world. This holds true for both adult and pediatric intensive care units. ${ }^{22,23}$ Longer duration of stay has been linked with various problems among the patients admitted in the ICU in the past. Poor outcome i.e. death in our study participants was strongly linked with the longer stay in the critical care unit. Reason might be infections or other ICU hazards or it may be the original intensity of trauma which contributed both in the longer ICU stay and the development of the fatal complications. More studies with the control of confounding factors may be required to clear this association.

\section{CONCLUSION}

Frequency of thrombocytopenia was high among patients admitted with trauma in intensive care unit and was also related to poor outcome in these patients.

\section{LIMITATION OF STUDY}

Patients were not followed up for long term after the discharge. More strict exclusion criteria could have excluded all the other co-morbidities which could contributed to thrombocytopenia so that exact link of trauma and ICU admission could be made with this phenomenon.

\section{Conflict of Interest: None.}

\section{Authors' Contribution}

AF: Article writing, EA: Data compiling, ZFB: Data compiling, UAS: Data compiling, TBT: Data compiling, AK: Data compiling

\section{REFERENCES}

1. Pogorzelski GF, Silva TA, Piazza T, Lacerda TM, Netto FA, Jorge $\mathrm{AC}$, et al. Epidemiology, prognostic factors, and outcome of trauma patients admitted in a Brazilian intensive care unit. Open Access Emerg Med 2018; 10(6): 81-88.

2. Rizwan M, Hashmi M, Zafar H. A Six-month Retrospective Study of Resources Burden by Trauma Victims in the Surgical Intensive Care Unit of a University Hospital in Pakistan. Cureus 2018; 10(8): e3236.

3. Kumar P, Jithesh V, Gupta SK. A comparative cost analysis of polytrauma and neurosurgery Intensive Care Units at an apex trauma care facility in India. Ind J Crit Care Med 2016; 20(7): 398-403.

4. Tomaiuolo M, Brass LF, Stalker TJ. Regulation of Platelet Activation and Coagulation and Its Role in Vascular Injury and Arterial Thrombosis. Interv Cardiol Clin 2017; 6(1): 1-12.

5. Ajibola SO, Akinbami A, Rabiu K. Gestational thrombocytopaenia among pregnant women in Lagos, Nigeria. Niger Med J 2014; 55(2): 139-143.

6. Guclu E, Durmaz Y, Karabay O. Effect of severe sepsis on platelet count and their indices. Afr Health Sci 2013; 13(2): 333338.
7. Naing C, Whittaker MA. Severe thrombocytopaenia in patients with vivax malaria compared to falciparum malaria: a systematic review and meta-analysis. Infect Dis Poverty 2018; 7(1): 10-14.

8. Golriz M, Ghamarnejad O, Khajeh E. Preoperative thrombocytopenia may predict poor surgical outcome after extended hepatectomy. Can J Gastroenterol Hepatol 2018; 2018(1): 1275720.

9. Khurana D, Deoke SA. Thrombocytopenia in Critically Ill Patients: Clinical and Laboratorial Behavior and Its Correlation with Short-term Outcome during Hospitalization. Ind J Crit Care Med 2017; 21(12): 861-864.

10. Agrawal S, Sachdev A, Gupta D, Chugh K. Platelet counts and outcome in the pediatric intensive care unit. Ind J Crit Care Med 2008; 12(3): 102-108.

11. Stephan F, Montblanc Jd, Cheffi A, Bonnet F. Thrombocytopenia in critically ill surgical patients: a case-control study evaluating attributable mortality and transfusion requirements. Crit Care 1999; 3(6): 151-158.

12. Koyama K, Katayama S, Muronoi T. Time course of immature platelet count and its relation to thrombocytopenia and mortality in patients with sepsis. PLoS One 2018; 13(1): e0192064.

13. Batool A, Tanveer A, Memon MI, Nazar CMJ, Tahir H. Frequency of ICU mortality and thrombocytopenia in patients with sepsis. J Prev Epidemiol 2016; 1(2): e14-e18.

14. Venkata C, Kashyap R, Farmer JC, Afessa B. Thrombocytopenia in adult patients with sepsis: incidence, risk factors, and its association with clinical outcome. J Intensive Care 2013; 1(1): 13-18.

15. World Health Organization (WHO). Health topic-Injuries. 2016. [Internet] Available from: https://www.who.int/news-room/ fact-sheets/detail/falls (Accessed on August 20 2017)

16. Mosleh M, Dalal K, Aljeesh Y, Svanström L. The burden of warinjury in the Palestinian health care sector in Gaza Strip. BMC Int Health Hum Rights 2018; 18(1): 28-31.

17. World Health Organization (WHO). Eastern Mediterranean situation report \#10. Conflict escalation in Gaza Strip- complex emergency, occupied Palestinian territories (OPTs). Gaza Strip: 2014, [Internet] Available from: https://www.un.org/unispal/ document/auto-insert-193700/(Accessed on August 20 2017)

18. World Health Organization. Global health risks: mortality and burden of disease attributable to selected major risks. Geneva:, 2009, [Internet] Available from: https://apps.who.int/iris/ handle/10665/44203(Accessed on August 20 2017)

19. Mishra B, Sinha Mishra ND, Sukhla S, Sinha A. Epidemiological study of road traffic accident cases from Western Nepal Ind J Commun Med 2010; 35(2): 115-121.

20. Boyle MJ, Smith EC, Archer FL. Trauma incidents attended by emergency medical services in Victoria, Australia. Prehosp Disaster Med 2008; 23(1): 20-28.

21. Babatunde AS, Adedeji OA, Chima PK, Sulyman AK, Ukpong $\mathrm{SU}$, Lukman OA, et al. Clinical spectrum of trauma at a university hospital in Nigeria. Eur J Trauma 2002; 28(3): 365-369.

22. Martini V, Lederer AK, Laessle C, Makowiec F, Utzolino S, Feigl $\mathrm{SF}$, et al. Clinical Characteristics and Outcomes of Surgical Patients with Intensive Care Unit Lengths of Stay of 90 Days and Greater. Crit Care Res Pract 2017; 2017(1): 9852017.

23. Alam MR, Haque M, Haque M. An Appraisal of Mortality in Intensive Care Unit of a Level III Military Hospital of Bangladesh. Indian Journal of Critical Care Medicine: Peer-reviewed, Official Publicat of Ind Soc Crit Care Med 2017; 21(9): 594-598. 